\title{
Older adults undergoing home enteral nutrition therapy: integration of national public policy and municipal programs
}

Rubia Daniela Thieme' ${ }^{1}$ (D)

Maria Eliana Madalozzo Schieferdecker ${ }^{2}$ (D) Rafael Gomes Ditterich ${ }^{3}$ ID

Abstract

Objective: to verify if national public policies and municipal programs contain elements that contribute to ensure the Human Right to Adequate Food (HRAF) of older adults undergoing home enteral nutrition therapy (HENT) and to propose the integration of these elements. Method: a qualitative study was carried out based on the content analysis of the documents of the National Policy for Older Adults (or PNI), the National Policy for the Health of Older Adults (or PNSPI) and the National Food and Nutrition Policy (or PNAN). Analysis of the relationships (co-occurrences) in programs of the 29 cities of the 2 nd regional health region of Paraná to provide care for people with special dietary needs (SDN), such as older adults undergoing HENT, was also carried out. For the analysis of the relationships, the keywords older adult and right were used. Furthermore, the integration of national public policies and municipal programs was proposed. Results: the PNI, PNSPI and PNAN contain converging principles, guidelines and actions, but they are not fully integrated into the programs. Only seven cities with programs that aimed to organize care involving SDN were identified, documented in five protocols and two decrees. A co-occurrence was verified in three of the analyzed documents, but a relationship between the keywords older adult and right was not verified in the protocols and decrees. In the integration proposal, a network was described, based around the goal of reaching the center, which represents the HRAF for older adults undergoing HENT. Conclusion: national public policies contain elements to ensure the HRAF of older adults undergoing HENT, but the municipal programs do not include all these elements. A proposal to integrate the elements was created.

\footnotetext{
Universidade Federal do Paraná, Programa de Pós-graduação em Políticas Públicas, Setor de Ciências Sociais Aplicadas. Curitiba, PR, Brasil.

2 Universidade Federal do Paraná, Programa de Pós-graduação em Alimentação e Nutrição, Departamento de Nutrição. Curitiba, PR, Brasil.

3 Universidade Federal do Paraná, Programa de Pós-graduação em Políticas Públicas, Setor de Ciências Sociais Aplicadas, e Programa de Pós-Graduação em Saúde Coletiva, Departamento de Saúde Comunitária. Curitiba, PR, Brasil
}

Keywords: Public Policy. Health of the Elderly. Enteral Nutrition. Homebound Persons. Program. 


\section{INTRODUCTION}

Special dietary needs occur due to metabolic or physiological disorders, either temporary or permanent, which cause alterations in the biological use of nutrients or the food consumption pathway. Enteral nutrition is one type of nutritional therapy (NT), and is available at every health care point in the Health Care Network (HCN) of the Brazilian National Health Service (or SUS), including Primary Care (PC) and home care ${ }^{1,2}$.

Home enteral nutrition therapy (HENT) can be recommended for clinically stable individuals at nutritional risk or suffering malnutrition who are unable to meet their nutritional needs through normal food intake, but have a functioning gastrointestinal tract. The goal of HENT is to improve or maintain nutritional status and functional capacity, as well as to increase quality of life ${ }^{1,3,4}$.

A greater frequency of older adults undergoing HENT has been observed in the last twenty years due to the high prevalence of chronic diseases, such as neoplasms and neurological diseases ${ }^{3,4}$. In the SUS, the organization and provision of care related to food and nutrition in cases of special dietary needs (SDN) and the implementation of Food and Nutritional Security (FNS), with the aim to guaranteeing the Human Right to Adequate Food (HRAF), are guided by the National Food and Nutrition Policy (or PNAN). In addition to the PNAN, other public policies can contribute to ensuring the right to health and the HRAF of individuals, especially for older adults undergoing HENT, such as the National Policy for Older Adults (or PNI) and the National Policy for the Health of Older Adults (or PNSPI) ${ }^{1}$, 2.5-7. Different policies must be adopted by public authorities to guarantee FNS, understood as the right of individuals, including specific population groups, to regular and permanent access to quality food, in sufficient quantities, without their access to other essential needs being compromised, with the aim of promoting health and nutrition ${ }^{6}$.

Thus, actions aimed at ensuring the FNS of older adults with SDN and undergoing HENT must consider the specific characteristics of this group. Adequate food, which is a fundamental right
$(\mathrm{HRAF})^{6}$, can be guaranteed by access to the foods required for the preparation of a diet administered via tube or commercial formulas for enteral nutrition ${ }^{3}$. In this sense, policies, such as the PNAN ${ }^{1}, \mathrm{PNI}^{5}$ and $\mathrm{PNSPI}^{7}$, and related programs can collaborate both in isolation and in an integrated manner to guarantee the HRAF of older adults undergoing HENT.

Public policies can be implemented through programs. In Brazil, municipal districts can implement such programs aimed at the nutritional care of people with SDN, including older adults undergoing HENT. However, it is important to verify the extent to which these policies and programs have registered a specific concern for the rights of older adults and to propose the integration of their actions. Therefore, the objective of this study was to verify if national public policies and municipal programs have elements that contribute to guarantee the HRAF of older adults undergoing HENT, and propose the integration of these elements.

\section{METHOD}

A qualitative study was carried out, employing the document analysis tool. The documents listed for the production of the data were the PNI, PNSPI and PNAN, as well as programs that implement the PNAN in municipal districts in Paraná. The protocols or regulations referring to programs of the municipal districts of the 2 nd regional health department of Paraná were analyzed, according to the divisions established by the State Health Department. In order to identify the provision of a program aimed at the nutritional care of people with SDN, a search was performed on a search engine and the official websites of the 29 municipal districts of the 2nd regional health department of Paraná between October 15th and 19th, 2019.

For searches on the electronic search site, the name of the municipal district was used together with the keywords: special food or special diets or nutritional formulas or enteral nutrition or nutritional therapy. On the websites of the Municipal Councils, a search by hyperlink was carried out to access the pages of the Municipal Health Departments (MHD), which, when available, were used to search for a 
program, program protocol, program regulations or correspondent. The search tool was used and the keywords: food, diet, formula, nutrition, nutritional, home or home-based were inserted.

The analysis of the content of the PNl, PNSPI and PNAN was carried out to qualitatively evaluate the information. The content analysis technique considers that everything that is written is suitable for analysis in order to obtain indicators that allow the inference of knowledge of the conditions of production/reception of the messages in question ${ }^{8}$. The analysis technique considered fragments that contained the elements necessary to ensure the HRAF of older adults undergoing HENT, which were extracted from the text.

The technique used to analyze the content of the protocols and regulations was the analysis of relationships, based on the analysis of cooccurrences approach. The relationships between the parts of a message were extracted from the text of the documents. The procedural sequence for co-occurrence analysis was: (a) choice of keyword and categorization by theme; (b) cutting of text into fragments; (c) presence or absence of keyword in each text fragment; (d) calculation of co-occurrences; (e) representation and interpretation of results ${ }^{8}$.

The keywords chosen were: older adult and right. The thematic categories of the study were established from the keywords. The text was cut in accordance with the presentation format of the document. For the protocols, two parts were considered for analysis: introduction and development. For regulations, the preliminary provisions and general provisions were considered. The co-occurrences were demonstrated quantitatively through the frequency of fragments that contained the two relevant terms. The qualitative interpretation of the results was performed considering the context, the document construction process and the definition of FNS and HRAF.

Based on the results obtained through documentary analysis, a proposal was developed to integrate the national policies and municipal programs. The extraction of the elements from the documents was carried out through content analysis using the older adult population as a guide and the definitions of the FNS and HRAF. This made it possible to locate and contextualize the information contained in the documents. The integration proposal was elaborated using the Visual Paradigm Online ${ }^{\circledR}$ program, in which the convergent elements identified in the documents were considered.

The documents referring to the programs are considered publicly accessible and their analysis does not require approval by the Ethics Committee for Research Involving Human Beings, according to National Health Council Resolution no. 510/2016?.

\section{RESULTS}

The analysis of the content of the PNI, PNSPI and PNAN documents revealed converging elements in policies, such as the prioritization of health care in PC, including home care (HC), social participation, the continuous education of health professionals, articulation between different sectors and the participation of entities of the federation in the allocation of resources ${ }^{1,5,7}$. The integration of these elements, which can be implemented through programs, can contribute to ensuring the HRAF of older adults undergoing HENT.

Programs designed to care for people with SDN can be national, state or municipal. Most often, municipal districts are responsible for formulating and executing these programs. In the 2 nd regional health department of Paraná, among the 29 municipal districts, seven $(\mathrm{N}=7 ; 24.1 \%)$ were identified as possessing a program aimed at organizing care for people with SDN. For five municipal districts, program protocols were identified, used to organize nutritional care for SDN in PC and HC, presented in the form of technical materials that guide the work processes of teams, while for two municipal districts, guidelines were identified, presented in the form of municipal decrees to establish programs, but which did not provide a detailed description of the team's work processes.

Through the analysis of the content of the protocols $(n=05)$, it was found that only one mentioned the keyword older adult in its introduction, but all mentioned it in their development sections. The keyword rightwas mentioned by three protocols in the introduction and three in the development sections. For the protocols, 
there was no relationship between the keywords. The analysis of the content of the decrees showed that in the preliminary provisions none mentioned the keyword older adult, the same result obtained for the general provisions, while the keyword right was observed in the preliminary provisions of one decree and in the general provisions of another. No relationship between the keywords was verified in the decrees. The number of citations of the keywords in the analyzed documents can be seen in Table 1.

Table 1. Year of implementation of the program or publication of the document, objectives of the programs, number of keywords and text fragments of the protocols and decrees of specific programs for the nutritional care of people with special dietary needs in the municipal districts of the 2nd regional health department of Paraná ( $\mathrm{N}$ = 07). Curitiba, Paraná, 2020.

\begin{tabular}{|c|c|c|c|c|}
\hline Year & Objectives & Document & Keywords & Fragments \\
\hline 2006 & $\begin{array}{l}\text { Promote nutritional and } \\
\text { health care }\end{array}$ & Protocol & $\begin{array}{l}\text { Older adult: } \\
\text { Eight } \\
\text { Right: Zero }\end{array}$ & $\begin{array}{l}\text {... the general nutritional recommendations used } \\
\text { in (program name) for the definition of the } \\
\text { nutritional needs of children, adolescents, adults } \\
\text { and older adults included in the program }\end{array}$ \\
\hline 2009 & $\begin{array}{l}\text { Monitor nutritional status } \\
\text { and provide manufactured } \\
\text { formulas for special } \\
\text { purposes }\end{array}$ & Protocol & $\begin{array}{l}\text { Older adult: } \\
\text { Three } \\
\text { Right: } \\
\text { Three }\end{array}$ & $\begin{array}{l}\text { Formula/Standard Supplement Adult/Older Adult } \\
\text {...adequate food is a fundamental human right, } \\
\text { inherent to the dignity of the person and } \\
\text { indispensable for the realization of the rights } \\
\text { enshrined in the Federal Constitution... }\end{array}$ \\
\hline 2014 & $\begin{array}{l}\text { Meet requests for special } \\
\text { diets and milks and } \\
\text { monitor nutritional status }\end{array}$ & Protocol & $\begin{array}{l}\text { Older adult: } \\
\text { One } \\
\text { Right: } \\
\text { Three }\end{array}$ & $\begin{array}{l}\text { Breastfeeding has a direct and indirect influence } \\
\text { on the control of diseases such as hypertension, } \\
\text { diabetes and obesity (health of the older adult) } \\
\text {... in this way it does not mean that the SUS should } \\
\text { treat everyone equally, but rather respect the rights } \\
\text { of everyone, according to their differences }\end{array}$ \\
\hline 2015 & $\begin{array}{l}\text { Provide/Dispense special } \\
\text { diets, supplements/ } \\
\text { food modules and infant } \\
\text { formulas and perform } \\
\text { patient follow-ups }\end{array}$ & Protocol & $\begin{array}{l}\text { Older adult: } \\
\text { Three } \\
\text { Right: Two }\end{array}$ & $\begin{array}{l}\text { Hypercaloric diet - For adult and older adult } \\
\text { patients in related clinical conditions... } \\
\ldots \text { of the Federal Constitution, states that "health } \\
\text { is the right of all and the duty of the State, } \\
\text { guaranteed through social and economic policies } \\
\text { aimed at reducing the risk of disease and other } \\
\text { diseases and access ... }\end{array}$ \\
\hline 2017 & $\begin{array}{l}\text { Contribute to assessment, } \\
\text { guidance, clinical and } \\
\text { nutritional monitoring and } \\
\text { the provision of infant } \\
\text { formulas, industrialized } \\
\text { enteral diets, dietary } \\
\text { supplements and nutrient } \\
\text { modules. }\end{array}$ & Decree & $\begin{array}{l}\text { Older adult: } \\
\text { Zero } \\
\text { Right: Two }\end{array}$ & $\begin{array}{l}\text { Considering that adequate food is a basic human } \\
\text { right, indispensable to ensure the provision of } \\
\text { the rights enshrined in the Federal Constitution, } \\
\text { it is up to the government to adopt policies and } \\
\text { actions that respect, protect, promote and provide } \\
\text { the human right to adequate and nutritional food } \\
\text { for the population }\end{array}$ \\
\hline 2019 & $\begin{array}{l}\text { Assess the need for the } \\
\text { use of food formulas and } \\
\text { monitor and evaluate } \\
\text { dietary treatment }\end{array}$ & Decree & $\begin{array}{l}\text { Older adult: } \\
\text { Zero } \\
\text { Right: One }\end{array}$ & $\begin{array}{l}\text { Registration for the receipt of Infant Formulas and } \\
\text { Oral and Enteral Food Supplements, the products } \\
\text { subject to this Program, will be evaluated by the } \\
\text { Nutritional Support Commission, with the following } \\
\text { categories of users having the right to register: Infants... } \\
\text { premature babies...children and adults... }\end{array}$ \\
\hline 2019 & $\begin{array}{l}\text { Provide infant formulas, } \\
\text { enteral diets and dietary } \\
\text { supplements/ modules }\end{array}$ & Protocol & $\begin{array}{l}\text { Older adult: } \\
\text { Three } \\
\text { Right: Six }\end{array}$ & $\begin{array}{l}\text { Older patients ( } \geq 60 \text { years old) will have } \\
\text { an individual assessment with malnutrition } \\
\text { considered to be BMI below } 22 \mathrm{~kg} / \mathrm{m}^{2} \\
\text { Therefore, all citizens, equally, must have their } \\
\text { rights to health guaranteed by the State }\end{array}$ \\
\hline
\end{tabular}

Created by the authors. Information for the chart obtained through content analysis of the documents (protocols and decrees) of the municipal programs for nutritional care for people with special food needs. 
From the analysis of the content of the protocols and decrees, it was observed that the keyword older adult was mentioned up to eight times, while the keyword rightwas mentioned up to six times (Table 1). Co-occurrence was verified in three of the analyzed documents. The keyword older adult was identified as associated with nutritional assessment, nutritional recommendations, description of commercial formulas for enteral nutrition, inclusion criteria for dispensing commercial formulas for enteral nutrition and for remaining in the program. The keyword right, meanwhile, was associated with life, health and adequate food, information, registration in the program for dispensing commercial formulas for enteral nutrition and equity.

From the analysis of the number of citations of the keyword right, it was observed that the guarantee of the HRAF of people with SDN is not referred to in the objectives of the programs. Although not included in the objectives, food and nutrition were mentioned as determinants and conditions of health, as well as basic requirements for its promotion and protection. In addition, the allusion to health as a right for all and a duty of the State was included in the text of three of the documents analyzed (Table 1).

The existence or absence of government actions to ensure the right to health and food were observed, according to the manner in which the protocols and decrees were systematized. As for the rights of the older adults, no document had a specific flow or inclusion criteria for people over 60 years of age. In the flows and criteria, the standardization of guidelines and conduct for the dispensing of products, such as infant formulas, commercial formulas for enteral nutrition, supplements and modules, is notable. Thus, the prioritization of guidelines for the organization of the supply of products can be seen, while the establishment of guidelines for nutritional care is absent.

The analysis of the documents indicated that the programs include criteria for the supply of commercial formulas for HENT, as well as recommendations for diets prepared with food for HENT, combined with nutritional guidance and monitoring. The responsibility for purchasing the necessary food for the preparation of the diet remains with the user undergoing HENT and their family, and nonadherence to the recommendation of the diet with food does not include the provision of commercial formula by the municipal district.

For the acquisition of food and preparation of the diet, a variety of resources are needed, among which are financial resources. One of the protocols analyzed contained the recommendation that in cases of primary malnutrition, health service users and family members should seek the Municipal Supply Department for more information about the actions provided, such as the provision of FNS equipment. This is notable for being an intersectoral action that could help low-income families.

The importance of knowing the socioeconomic situation of users was observed in most of the documents analyzed. In terms of the criteria for inclusion and remaining in the program, family income appeared in three of the documents. In one program, family income was not considered. However, in two programs, the inclusion criteria took family income into account. According to the protocol and decree, to be included in the program, the user must have a family income of up to three times the minimum wage.

Considering the situations of social vulnerability and the need to ensure the FNS of people with SDN, this study proposes the integration of different policies and programs to guarantee the HRAF of elderly people undergoing HENT. The proposal presented in Figure 1 demonstrates the integration of the PNI, PNSPI, PNAN and specific programs for the nutritional care of people with SDN from seven municipalities in the 2 nd regional health region of Paraná.

The elaboration of the integration proposal included 28 elements extracted from the documents submitted to content analysis. Four elements were extracted from the PNI, nine from the PNSI, twelve from the PNAN and three from the municipal programs.

The integration of these elements extracted from public policies and municipal programs can contribute to ensuring the HRAF of elderly people undergoing HENT. Interlocution was identified 
in 24 of the elements, notably those that refer to integrated care, access to health, respect for the user's autonomy and the continuous education of health professionals.

There was little integration of the PNI, PNSPI and PNAN with the protocols and decrees. Following the identification of the limited incorporation of the principles, guidelines, objectives and actions of these public policies into the municipal programs, a proposal for the integration of their elements was elaborated, also aimed at the municipal programs analyzed, with a view to ensuring the HRAF of elderly people undergoing HENT.

The integration of different policies and programs was represented graphically by a network. The principles, guidelines, objectives and actions of the PNI, PNSPI, PNAN and the municipal programs were placed in circles, which are linked with the purpose of attaining the center, representing the HRAF of older adults undergoing HENT. Thus, in the presentation of the network integration, the necessary elements to ensure the HRAF of older adults undergoing HENT can be observed.

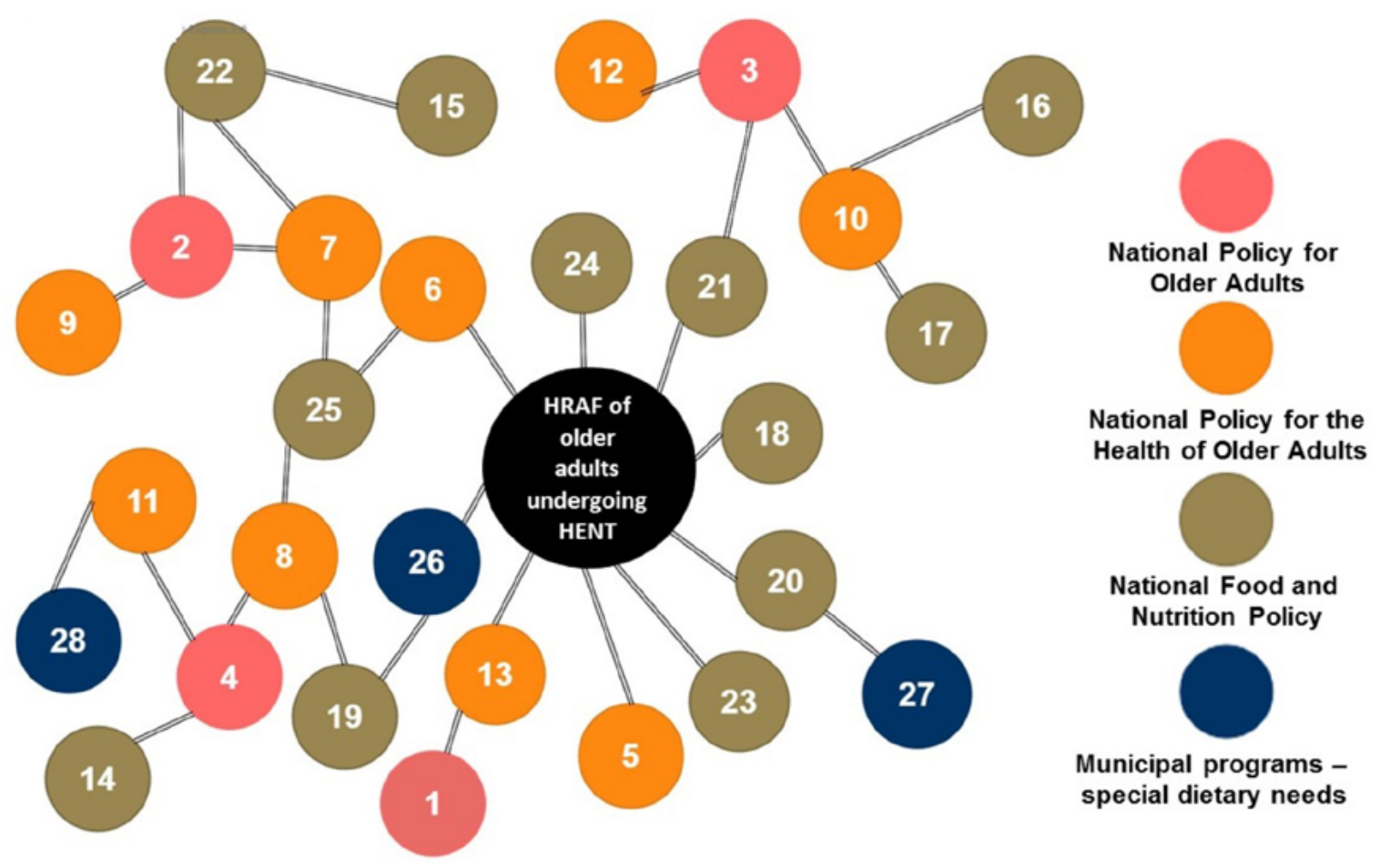

Figure 1. Proposal for the integration of the National Policy for Older Adults, the National Policy for the Health of Older Adults, the National Food and Nutrition Policy and the municipal programs of care for special dietary needs to guarantee the Human Right to Adequate Food (HRAF) of older adults undergoing Home Enteral Nutritional Therapy (HENT). Curitiba, Paraná, 2020.

Key: HRAF: Human Right To Adequate Food; HENT: Home Enteral Nutritional Therapy; 1. Duty of family, society and the State to ensure the rights of citizenship; 2. Human resources training; 3. Participation of older adult in policy cycle; 4. Health care for older adults; 5. Line of care and bidirectional flows - increase the quality and resolutive capacity of Primary Care; 6. Adequate physical infrastructure and supplies; 7. Technical skills; 8. Prevention, rehabilitation and recovery actions. Prevention and early intervention rather than curative interventions; 9. Multiprofessional care; 10 . Wishes of older adults and their family; 11. Specific care for frail older adults; 12 . Participation and strengthening of social control; 13. Social Security, Unified Social Assistance and Justice and Human Rights System; 14. Principles of National Health Service; 15. Food as an element of humanization; 16. Respect for diversity and food culture; 17 . Strengthening of autonomy; 18. Social determination and the interdisciplinary and intersectoral nature of food and nutrition; 19. Organization of Nutritional Care, promotion of adequate and healthy food, food and nutritional surveillance. 20. Management of Food and Nutrition Actions; 21.Participation and Social Control; 22. Workforce Training; 23. Food Control and Regulation; 24. Research, innovation and knowledge in food and nutrition; 25. Ministry of Health, Municipal and State (including the Federal District) Health Departments; 26. Promote nutritional care and general health care for people with special dietary needs; 27. Provision of commercial formulas for enteral nutrition; 28. Conducting home visits

Source: authors. 


\section{DISCUSSION}

The present study identified elements of the PNI, PNSPI, PNAN and municipal programs and proposed the integration of national public policies and municipal programs to ensure the provision of FNS in order to guarantee the HRAF of older adults undergoing HENT. The PNI, PNSPI and PNAN have converging elements which consider the rights of older adults. In the protocols and decrees of the municipal programs, fewer elements that contribute to guaranteeing the HRAF of older adults undergoing HENT were extracted than were taken from the PNSPI and PNAN, while there was also a low frequency of citation of the keywords older adult and right.

In the municipal programs, greater emphasis was placed on clinical conditions and diseases that affect children. The older adults and their possibly specific SDN were not explicitly mentioned in the texts, nor was there any mention of the Statute for the Elderly or the PNSPI. However, chronic noncommunicable diseases (NCDs) commonly found in the population group aged over 60 years were mentioned, as well as the recommendation of NT due to their symptoms or sequelae.

The Ministry of Health recommends that each location (municipal location or service) must define its own care protocol for SDN, as it contributes to the efficiency and effectiveness of health management, in addition to functioning as a regulatory and equity tool in the dispensing of supplies ${ }^{2}$. The actions for the nutritional care of people with SDN, established through programs, are described in greater detail in the protocols than in the decrees.

The protocols provide transparency to the inclusion and exclusion criteria, as well as the line and flow of care, with a view to guaranteeing respect for the principles of the SUS and the reach of the HRAF. However, the protocols analyzed in the present study did not consider the circumstances of senescence and senility and the specific rights of the older adults when organizing the standardization of home care.

Most older adults in Brazil reside in private households, with their spouse, families or alone ${ }^{10}$.
Older adults have specific care needs, which are due to the characteristics of the presentation, installation and outcome of health problems. Considering the high prevalence of NCDs in the Brazilian population aged over 60 , as well as their sequelae, functional limitations and disabilities, the provision of health care, including HENT, at home may be necessary ${ }^{7,11}$. In this sense, the increase in the number of older adults undergoing HENT has been demonstrated by different studies carried out in Brazil and other countries ${ }^{3,4}$.

In the international scenario, older Americans and Europeans have reported the need for more information about their health conditions and for clearer communication about proposed diagnoses and treatments ${ }^{12}$. As part of the communication process, health professionals must train informal caregivers to provide health care at home.

Support for informal caregivers for training in home care for older adults, especially after hospital discharge, can be carried out by telephone contact with nursing professionals to identify needs, provide guidance and information and answer questions about existing resources ${ }^{13}$. In the case of HENT care, in addition to training related to technical care, programs and their protocols must include periodic monitoring of older adults with a view to providing security and comfort through the establishing of a bond.

Bonding and effective communication between health service users and professionals help to improve health decision making. In communication, the health professional should avoid technical terms, divide information into stages and assess the understanding of users ${ }^{14}$. In PC, a bond is a condition for the proper functioning of the service in terms of accountability and the longitudinality of care, in addition to improving adherence to therapy and encouraging home visits ${ }^{15}$. During home visits, the discharge guidelines can be reinforced or reformulated, especially with reference to $\mathrm{HENT}^{16}$.

For communication between health professionals and HENT patients, their caregivers and family members, professionals require technical and scientific training. In accordance with the Guidelines of the European Society for Clinical Nutrition and Metabolism (ESPEN) on HENT, all healthcare 
professionals directly involved in patient care must receive education and training relevant to their roles on the different aspects related to $\mathrm{HENT}^{3}$. Staff education and training should be among the goals of health services.

An example of the training in HENT of nutritionists working in a nutritional care program for SDN was the hiring of a company specialized in courses and in the preparation of manuals/protocols by a MHD of the municipal districts included in this study. From the nutritional care manual, the municipal protocol was constructed. As part of the professional development strategy, a partnership was also formed with a university, for continuous education. However, training in specific care for older adults was not mentioned ${ }^{17}$, even though it is recommended by the Statute for Older Adults ${ }^{18}$.

In this sense, it is essential that health professionals are properly trained to provide health care for the older population. However, in order to overcome the logic of training, improvements and updates, Continuous Education in Health (CEH) must also be provided. CEH can occur in home visits, during case discussions, in operational groups, in the informal work routine and via the matrix ${ }^{19}$.

Matrix support in health aims to ensure specialized assistance and technical and pedagogical support to the reference teams. The implementation process of Matrix Support in the Health of Older Adults in the city of Vitória, Espírito Santo, was reported in the study by Madureira and Bissoli ${ }^{20}$, which showed that matrix support collaborated in the creation of flows and the organization of the HCN for the older population, in addition to increasing the safety of the PC teams in dealing with and resolving cases, improving care for older adults and providing interdisciplinary discussion ${ }^{20}$.

Teamwork is interdisciplinary and multiprofessional and must ensure standardized and coordinated care for all people who need $\mathrm{HENT}^{3}$. The absence of a professional in a team hinders integral care in PC, compromising the resolvability of the care provided ${ }^{3,21}$. In this sense, since the integral health care for older adults in the SUS is guaranteed by the Statute for the Elderly $^{18}$, the nutritionist is key to achieving it.
The role of the nutritionist has been considered a reference in the process of matrix-based strategies in Food and Nutrition and can contribute to the organization of PC. Among the actions of nutritionists are those aimed at the training of teams with a focus on NCDs and promoting health at all stages of life. In addition, the actions of Food and Nutrition that seek integrality need to go beyond the biological and causal dimension ${ }^{22,23}$, including in care involving HENT.

The act of eating through HENT is not only biological, with the sole objective of meeting nutritional needs, but is also socio-cultural. In this sense, the social characteristics, the food culture, the preferences and desires of older adults and the family, as well as the often stable clinical situation of the individual undergoing HENT are important for decision-making regarding health care and nutrition interventions in this treatment mode ${ }^{24}$ and should be considered in programs aimed at the nutritional care of people with SDN.

The present study demonstrated that the municipal programs analyzed prioritize the use of food-based diets for HENT, unlike European guidelines, which claim that diets with food are less effective and less safe than commercial formulas ${ }^{3}$. However, the recommendation of the ESPEN emphasizes the biological dimension, without considering the social, cultural and economic aspects, which also form part of the effectiveness of the FNS. The protocols and decrees analyzed in the present study also prioritized the biological and technical aspects of food.

The principles of FNS should be considered in home-based health care models. To ensure the HRAF, the cultural meanings of diet for older adults undergoing HENT and their families and socioeconomic aspects must be respected in order to provide physical, psychological and social wellbeing, as well as quality of life $^{24}$, which should be evaluated periodically ${ }^{3}$.

Different factors can influence the quality of life of people undergoing HENT, such as their clinical conditions and the duration of the administration of enteral nutrition. It has, however, been shown that enteral nutrition can improve the quality of life $^{25}$. 
In order for the goal of maintaining or improving quality of life to be achieved, the early onset of NT is recommended, as soon as the nutritional risk is identified. Nutritional screening should be routinely implemented for the early detection of the risk of malnutrition. In $\mathrm{HC}$, specific tools for the nutritional screening of older adults should be used ${ }^{26}$, something which was not considered in the programs analyzed.

After nutritional screening, the nutritional assessment of older adults can be performed. Tavares et al. ${ }^{27}$ highlighted the challenges for diagnosing and monitoring the nutritional status of people over 60 in PC. The procedures performed are those recommended by the Food and Nutrition Surveillance System, which emphasize the use of anthropometric measures. Other indicators of nutritional status should be used by health professionals in a critical and integrated manner, considering the specific characteristics of older adults ${ }^{27}$.

Still, such individual characteristics of older adults undergoing HENT can make it difficult to apply techniques for nutritional assessment, especially those for anthropometric and body composition assessment, as it is common for older adults to be bedridden or suffer difficulties with mobility. These conditions increase the vulnerability of older adults, together with the consideration that vulnerable older adults have greater difficulty in performing activities of daily living ${ }^{28}$.

Vulnerability is also associated with Food and Nutrition Insecurity (FNI). Thieme et al. ${ }^{29}$ found that $50 \%$ of the homes of people undergoing HENT were classified as suffering FNI. To verify the FNI of households where older adults undergoing HENT live, validated instruments can be used, such as the Brazilian Food Insecurity Scale, which can be applied by health professionals in order to action other sectors.

Therefore, intersectoral articulation between the area of FNS and health is necessary. PNAN is considered an articulator between the two fields and the organization of nutritional care within the scope of the SUS. However, the predominance of the biomedical model is the main impediment to the effectiveness of the PNAN. To consolidate intersectoral articulation, strategies that go beyond sectoral programs ${ }^{30}$ must be formulated, in order to ensure FNS and guarantee HRAF. In this sense, the expansion of coverage of care services and in the field of FNS can contribute to the guarantee of the HRAF of older adults undergoing HENT and their families.

Financial access to adequate food is one of the main aspects of the effectiveness of FNS. According to the analysis of the protocols and decrees carried out in the present study, it was observed that the municipal districts are not responsible for providing the food that will be used for the preparation of an enteral diet.

The matter must be evaluated by the three spheres of management in the system in order to establish policies that can resolve this need. The attention to SDN in the SUS, then, is up to the states of Brazil and, more often, to the municipal districts. Greater municipal autonomy is the result of political-administrative decentralization, one of the principles of the SUS. However, financing is a barrier to the advancement of decentralization, as the municipal authority is left with greater expenditure and budgetary commitment ${ }^{31}$.

In this sense, in the present study, the rationalization of public spending was observed as one of the justifications for the elaboration of program protocols and the need to establish programs via decree. The Ministry of Health states that the management of supplies for HENT is aimed at the proper use of public resources, but that the best provision of care to SUS users must be made through protocols, lines of care and budgetary resources ${ }^{2}$. Thus, the importance of the SUS in promoting equity $^{32}$ is highlighted. In turn, the allocation of public resources must prioritize older adults, with a view to their protection ${ }^{18}$ and care, since, for example, there is a reduction in mortality among older adults when strategies based on PC care are implemented ${ }^{33}$. In addition, the development of regional health care strategies is important due to the different socioeconomic characteristics of the regions of Brazil ${ }^{34}$, which should be considered in the programs for the care of older adults with SDN. 
The present study has certain limitation, including the inclusion of programs from a single region in Brazil, the low number of municipal programs analyzed and the lack of triangulation of methods and data, which may mask results regarding the effectiveness of the municipal programs. The low number of municipal districts is justified by the fact that few such authorities have programs for care involving HENT in Paraná. Despite the limitations, however, to date no other studies have been found that present the content analysis of municipal programs with a view to caring for the SDN of older adults.

\section{CONCLUSION}

The national public policies analyzed present elements that contribute to guaranteeing the HRAF of older adults undergoing HENT, while the municipal programs do not include all the elements proposed on a national basis. A proposal to integrate these elements was created, and can be used in the future in the formulation of municipal programs to implement national public policies.

Edited by: Ana Carolina Lima Cavaletti

\section{REFERENCES}

1. Brasil. Ministério da Saúde; Secretaria de Atenção à Saúde. Política Nacional de Alimentação e Nutrição [National Policy for Food and Nutrition]. Brasília, DF: MS; 2013. Portuguese.

2. Brasil. Ministério da Saúde; Secretaria de Atenção à Saúde. Cuidados em terapia nutricional [Care in Nutritional Therapy ]. Brasília, DF: MS; 2015. Portuguese.

3. Bischoff SC, Austin P, Boeykens K, Chourdakis M, Cuerda C, Jonkers-Schuitema C, et al. ESPEN guideline on home enteral nutrition. Clin Nutr. 2020;39(1):5-22.

4. Mazur CE, Zago RCC, Schieferdecker MEM, Maluf EMCP. Home enteral nutrition: clinical-nutritional analysis and outcomes of 10 years of public policy. Nutr Hosp. 2019;36(4):758-63.

5. Brasil. Lei no 8.842 , de 4 de janeiro de 1994. Dispõe sobre a Política Nacional do Idoso, cria o Conselho Nacional do Idoso e dá outras providências [Provides on the National Policy of the Elderly, creates the National Council of the Elderly and gives other provisions]. Diário Oficial da União. 5 jan. 1994. Available from: http://www.planalto.gov.br/ ccivil_03/leis/L8842.htm Portuguese.

6. Brasil. Conselho Nacional de Segurança Alimentar e Nutricional. Lei no 11.346, de 15 de setembro de 2006. Cria o Sistema Nacional de Segurança Alimentar e Nutricional-SISAN com vistas em assegurar o direito humano à alimentação adequada e dá outras providências [Establishes the National Food and Nutrition Security System-SISAN with a view to ensuring the human right to adequate food and other measures]. Diário Oficial da União, 18 set. 2006. Portuguese.

7. Brasil. Ministério da Saúde. Portaria no 2.528 de 19 de outubro de 2006. Aprova a Política Nacional de Saúde da Pessoa Idosa [Approves the National Health Policy of the Elderly]. Diário Oficial da União. 20 out. 2006. Disponível em: http://bvsms.saude.gov.br/ bvs/saudelegis/gm/2006/prt2528_19_10_2006.html Portuguese.

8. Minayo MCS. O desafio do conhecimento. Pesquisa qualitativa em saúde [The knowledge challege. Qualitative Health Research]. Rio de Janeiro: HUCITEC-ABRASCO; 1992. Chap. 4. Fase de análise ou tratamento do material [Analysis or treatement phase of the material]. Portuguese.

9. Brasil. Conselho Nacional de Saúde. Resolução CNS n. ${ }^{\circ}$ 510, de 07 de abril de 2016. Dispõe sobre as normas aplicáveis a pesquisas em Ciências Humanas e Sociais [provides for applicable standards in the Human and Social Sciences]. Diário Oficial da União, $n^{\circ}$ 98. 24 maio 2016. Portuguese.

10. Camarano AA, Barbosa P. Instituições de Longa Permanência para Idosos no Brasil: do que está se falando? [Long-term care facilities for elderly in Brazil: what are you talking about?] In: Alcântara AO, Camarano AA, Giacomin KC. Política nacional do idoso: velhas e novas questões [National policy for the elderly: old and new isssues]. Rio de Janeiro: Ipea; 2016. Portuguese.

11. Instituto Brasileiro de Geografia e Estatística. Pesquisa Nacional por Amostra de Domicílios. Um Panorama da Saúde no Brasil. Acesso e utilização dos serviços, condições de saúde e fatores de risco e proteção à saúde, 2008 [National Household Sample Survey. An Overview of Health in Brazil. Access to and use of services, health conditions, risk factors and health protection, 2008]. Rio de Janeiro: IBGE, 2010. Portuguese. 
12. McGilton KS, Vellani S, Yeung L, Chishtie J, Commisso E, Ploeg J, et al. Identifying and understanding the health and social care needs of older adults with multiple chronic conditions and their caregivers: a scoping review. BMC Geriatrics 2018;18(1):1-6.

13. Slatyer S, Aoun SM, Hill KD, Walsh D, Whitty D, Toye C. Caregivers' experiences of a home support program after the hospital discharge of an older family member: a qualitative analysis. BMC Health Serv Res. 2019;19(1):1-10.

14. Hersh L, Salzman B, Snyderman D. Health Literacy in Primary Care Practice. Am Fam Physician. 2015;92(2):1-10.

15. Barbosa MIS, Bosi MLM. [Bond: a problematic concept in the Collective Health area]. Physis. 2017;27(4):1003-22. Portuguese.

16. Thieme RD, Pinto LM, Macedo DS, Palm RCM, Schieferdecker MEM. Development and implementation of responsible discharge care protocol for hospitalized elderly with chronic diseases and in need of special nutritional support. Demetra 2014;9(Supl.1):269-86.

17. Schieferdecker MEM, Pinheiro PARG, Lucas AC, Gomes KSG, Mazur CE. [Nutritional care program: historic landmark in public policy for people with special dietary needs in the City of Curitiba, Parana State, Brazil]. Demetra. 2014;9(Supl.1):287-96. Portuguese.

18. Brasil. Lei no 10.741 , de $1^{\circ}$ de outubro de 2003. Dispõe sobre o Estatuto do Idoso e dá outras providências [provides on the Statute of the Elderly and makes other provisions]. Diário Oficial da União. 3 dez. 2003. Available from: http:// www.planalto.gov.br/ ccivil_03/leis/2003/L10.741.htm Portuguese.

19. Nogueira IS, Acioli S, Carreira L, Baldissera VDA. Older adult care: permanent education practices of the Family Health Support Center. Rev Esc Enferm USP. 2019;53:e03512.

20. Madureira RMS, Bissoli SM. Apoio matricial em saúde do idoso: a experiência do município de VitóriaES [Matrix support in elderly health: the experience of the municipality of Vitória-ES]. In: Pinheiro R, Lopes TC, Silva FH, Silva Junior AG, Orgs. Experienci(ações) e práticas de apoio e a integralidade no SUS: por uma estratégia de rede multicêntrica de pesquisa [Experience(actions) and practices of support and integrality in SUS: for a multicentric research network strategy]. Rio de Janeiro: EpescAbrasco; 2014, p. 135-47. Portuguese.
21. Costa JP, Jorge MSB, Vasconcelos MGF, de Paula ML, Bezerra IC. [Solvability of the caretaking in primary care: multiprofessional articulation and services network]. Saúde Debate. 2014;38(103):733-43. Portuguese.

22. Fittipaldi ALM, Barros DC, Romano VF. [Matrix Support in Food and Nutrition actions: the perspective of professionals of the Family Health Strategy ]. Physis. 2017;27(3):793-811. Portuguese.

23. de Geus LMM, Maciel CS, Burda ICA, Daros SJ, Batistel S, Martins TCA, et al. [The importance of the insertion of the nutritionist on the Family Health Strategy]. Ciênc Saúde Colet. 2011;16(Suppl 1):797804. Portuguese.

24. Mazur CE, Schmidt ST, Rigon SA, Schieferdecker MEM. [Home Enteral Nutrition Therapy: interface between human right to adequate food and food security and nutrition]. Demetra. 2014;9(3):757-69. Portuguese.

25. Ojo O, Keaveney E, Wang XH, Feng P. The Effect of enteral tube feeding on patients' health-related quality of life: a systematic review. Nutrients 2019;11(5):1-.

26. Volkert D, Berner YN, Berry E, Cederholm T, Coti Bertrand P, Milne A, et al. ESPEN Guidelines on Enteral Nutrition: Geriatrics. Clinical Nutr. 2006;25(2):330-60.

27. Tavares EL, dos Santos DM, Ferreira AA, de Menezes MFG. [Nutritional assessment for the elderly: modern challenges]. Rev Bras Geriatr Gerontol. 2015;18(3):643-50. Portuguese.

28. Barbosa KTF, Costa KNFM, Pontes MLF, Batista PSS, de Oliveira FMRL, Fernandes MGM. [Aging and individual vulnerability: a panorama of older adults attended by the family health strategy]. Texto Contexto Enferm. 2017;26(2):e2700015. Portuguese.

29. Hieme RD, Lima JH, Rabito EI, Ditterich RG, Schieferdecker MEM. Home Nutritional Therapy and Food Insecurity. Abstracts of the 41st ESPEN Congress, Krakow, Poland, 31 August-3 September, 2019. Clinical Nutrition 2019;38:59-1-10.

30. Rigon AS, Schmidt ST, Bógus CM. [Nutritional challenges in the Brazilian Unified National Health System for building the interface between health and food and nutritional security]. Cad Saúde Pública. 2016;32(3):e00164514. Portuguese.

31. Pinafo E, Carvalho BG, Nunes EFPA. [Decentralization of health management:the path traveled to date, problematic points and prospects]. Ciên Saúde Colet. 2016;1(5):1511-24. Portuguese. 
32. Almeida APSC, Nunes BP, Duro SMS, Lima RCD, Facchini LA. [Lack of access and the trajectory of healthcare use by elderly Brazilians]. Ciênc Saúde Colet. 2020;25(6):2213-26. Portuguese.

33. Borim FSA, Francisco PMSB, Neri AL. [Sociodemographic and health factors associated with mortality in community-dwelling elderly]. Rev Saúde Pública. 2017;51(42):1-12. Portuguese.
34. Szwarcwald CL, de Souza Júnior PRB, Marques AP, de Almeida WS, Montilla DER. Inequalities in healthy life expectancy by Brazilian geographic regions: findings from the National Health Survey, 2013. Int J Equity Health. 2016;15(141):1-9. 